\title{
Landscape context modulates alien plant invasion in Mediterranean forest edges
}

\author{
Pablo González-Moreno • Joan Pino • \\ Núria Gassó • Montserrat Vilà
}

\begin{abstract}
Natural habitats in human-altered landscapes are especially vulnerable to biological invasions, especially in their edges. We aim to understand the influence of landscape and local characteristics on biological invasions by exploring the level of plant invasion and alien species traits in forest edges in highly urbanized landscapes. We identified all plant species in 73 paired plots in the edge and $50 \mathrm{~m}$ towards the interior of the forest. We explored the association between alien species richness and similarity in species composition between edge and interior plots with landscape and local variables, using generalized linear models and variance partitioning techniques. Then, we performed Fourth-corner analyses to explore the association between alien plant traits and local and landscape variables. In contrast to native species richness, alien species richness was more affected by the surrounding landscape than by the local
\end{abstract}

Electronic supplementary material The online version of this article (doi:10.1007/s10530-012-0306-x) contains supplementary material, which is available to authorized users.

P. González-Moreno $(\bowtie) \cdot$ M. Vilà

Estación Biológica de Doñana, Centro Superior de Investigaciones Científicas (EBD-CSIC), Av. Américo Vespucio S/N, 41092 Sevilla, Spain

e-mail: pgonzalez@ebd.csic.es

J. Pino · N. Gassó

Centre for Ecological Research and Forestry Applications (CREAF), Universitat Autònoma de Barcelona, 08193

Cerdanyola del Vallès, Catalonia, Spain characteristics of the edge. Road proximity was positively associated with alien species richness and proportion and was its most important correlate, whereas disturbance was negatively associated with native species richness and was its most influential factor. Alien plant traits were also primarily associated with landscape characteristics. For instance, species of Mediterranean origin and introduced for agriculture were associated with higher agriculture use in the landscape. Our findings suggest that risk analyses of habitat vulnerability to invasion must consider the landscape context in order to successfully predict highly invaded areas and identify potentially successful invaders.

Keywords Alien plant species - Level of invasion Edge effects $\cdot$ Forest fragmentation $\cdot$ Species traits

\section{Introduction}

Biological invasions and human-induced landscape changes are two major drivers of global change, affecting biodiversity both independently and synergistically (Didham et al. 2007). For example, humanderived land-uses can facilitate plant invasions in their surrounding natural habitats because they directly promote human frequentation and habitat disturbances that favour alien plant establishment (Hobbs and Huenneke 1992; Guirado et al. 2006). Furthermore, these human-derived land-uses can also increase 
propagule pressure from the human-transformed land matrix to the remaining patches of natural habitat (Deutschewitz et al. 2003; Ohlemüller et al. 2006; Gassó et al. 2009). Peri-urban forest edges offer an excellent study system to explore the synergistic effect of human-driven landscape alteration and plant invasion given that the urban-forest edge is the invasion front for many alien species. Due to their specific environmental conditions, edges are usually highly invaded in comparison to the forest interior (Harper et al. 2005; Vilà and Ibáñez 2011). The suitability of this habitat combined with high propagule pressure of specific alien plant species from urban areas (e.g. shade-tolerant species of gardening origin) might lead to further invasion of natural areas (Martin et al. 2009).

The adjacent landscape matrix might greatly influence the level of plant invasion in forest edges (Cadenasso and Pickett 2001; Harper et al. 2005; Ewers and Didham 2006; Vilà and Ibáñez 2011). A higher number of alien species have been found in forest edges adjacent to urban areas compared to agriculture areas (Guirado et al. 2006) given that these areas may provide propagules from a larger number of ornamental species. Other landscape characteristics that might positively affect the level of invasion include, for example, the proximity of roads (e.g. Bradley and Mustard 2006; Ibáñez et al. 2009) and land-use diversity (e.g. Pino et al. 2005; Kumar et al. 2006). Furthermore, landscape alteration may also affect differences in the level of invasion between the forest edge and the interior due to changes in species' percolation. Although this hypothesis is inherent to some neutral landscape approaches derived from percolation theory (With 2004), it remains largely unexplored. Highly altered landscapes supporting high alien propagule pressure might increase the percolation of alien species and therefore reduce the similarity in species composition between edge and interior forest communities.

Despite the recent evidence for the relevance of landscape shaping plant invasions (Vilà and Ibáñez 2011), the relative importance of landscape characteristics versus local characteristics in forest edges remains unclear (Bartuszevige et al. 2006). Local characteristics operating at the edge, such as microclimate conditions (e.g. light conditions) and species interactions (e.g. seed dispersal), could affect alien species establishment and spread (Harper et al. 2005).

The success of alien species in the process of invasion (i.e. invasiveness) has been related to particular biological and life-history species traits (Hayes and Barry 2007; Pyšek and Richardson 2007; Gassó et al. 2009). However, few studies have linked these traits with environmental factors at the invaded sites (Thuiller et al. 2006; Jauni and Hyvönen 2012), and to our knowledge, none have examined the relationship between specific alien plant traits and the local and landscape characteristics of forest edge habitats. Extrinsic traits such as the introduction pathway could determine the invasion success in forest edges. For example, Brothers and Spingarn (1992) observed that alien species introduced for agriculture were limited to the first few meters of the forest edge, whereas species used for gardening were mainly found in the forest interior probably due to a combination of dispersal and light limitations. Understanding these associations might be important to the improvement of invasion risk analyses customized for different habitats or landscape characteristics.

To provide insights on landscape and habitat management towards the prevention of plant invasions in forest edges, we compared plant invasion patterns between forest edges and forest interior in highly fragmented peri-urban forest areas. Specifically, we asked the following questions: (1) What are the main landscape and local factors explaining the level of plant invasion in forest edges? (2) Do landscape and local characteristics affect species similarity between the forest edge and the interior? (3) Are there differences in alien species traits between the forest edge and the interior? And finally, (4) are alien plant traits in forest edges related to landscape and local characteristics?

\section{Methodology}

Study site

The study area covers 35,000 ha in Vallès county (Catalonia, Northeast Spain), located $25 \mathrm{~km}$ north of Barcelona city (Fig. 1). Elevation ranges from 130 to $815 \mathrm{~m}$ a.s.l. and mean annual precipitation ranges from 600 to $800 \mathrm{~mm}$. During the last century, the landscape of this region has gone through a significant transformation, primarily due to agriculture abandonment and increasing urban sprawl related to the expansion of Barcelona's Metropolitan area (Olarieta et al. 2008). This land-use change has shaped a 


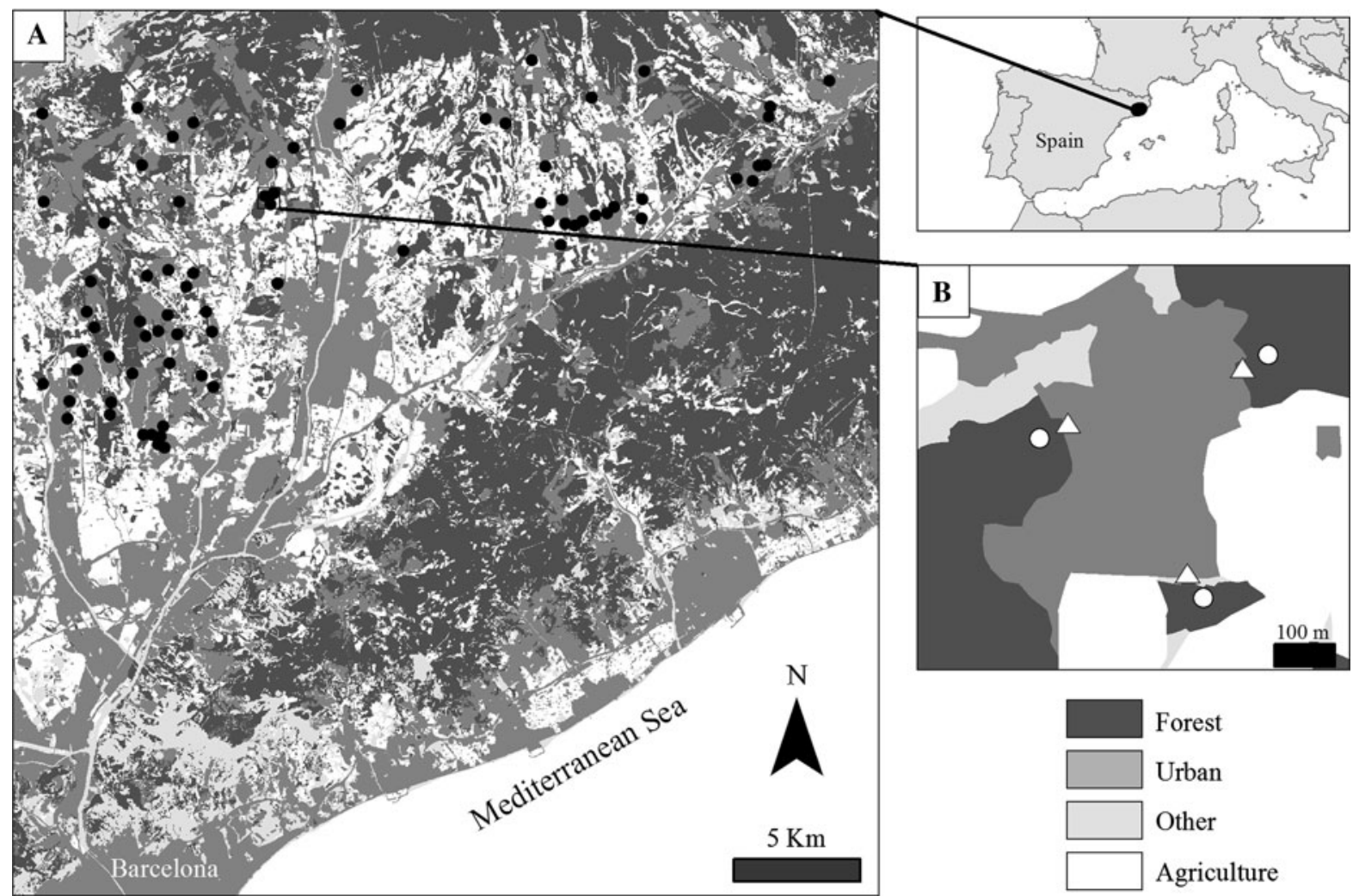

Fig. 1 Location of the study area in Vallès County, Catalonia, NE Spain and sampling protocol (European Datum 1950). a Black dots correspond to surveyed vegetation plots. b White circles indicate forest interior plots and white triangles edge plots

complex landscape mosaic with highly fragmented forests nested within a matrix of low-density urbanized and agricultural lands.

\section{Plant species survey}

We selected, by ortho-image interpretation of landscapes, 73 forest patches with contrasting human influence, ranging from agroforestry mosaics to urban surroundings (Fig. 1). Forests corresponded to mixed stands of pine (Pinus halepensis Mill., P. pinea L., $P$. nigra Arn.), the evergreen Quercus ilex L. and the deciduous $Q$. cerrioides Willk. In the most invaded location of each patch edge we set up a $10 \mathrm{~m}$ radius plot and another plot $50 \mathrm{~m}$ towards the forest interior (Fig. 1). Plant community effects are suggested to mostly disappear $50 \mathrm{~m}$ into the forest (Brothers and Spingarn 1992; Fraver 1994), although other effects could persist up to 100-500 m (Harper et al. 2005; Guirado et al. 2006). This setup might bias the comparison of species richness between the forest edge and interior, however, it should not affect the species traits occurrence or the predictors explaining plant community structures which constitute part of our main objectives. For each plot, we identified and classified all plant species as native or alien according to Bolós et al. (1993) and we calculated native and alien species richness and alien species proportion. We also calculated Sørensen's species similarity index (S) for native and alien species between edge and interior plots (McCune and Grace 2002) (Eq. 1):

$\mathrm{S}=2 \mathrm{C} / \mathrm{A}+\mathrm{B}$

where $\mathrm{A}$ and $\mathrm{B}$ are the number of species in the edge and interior plots, respectively, and $\mathrm{C}$ is the number of species shared by the two plots. The Jaccard's similarity index was also calculated and used in the analyses, but as it yielded similar results to Sørensen's index, we do not present the results for simplicity.

A set of plant species traits and factors related to the introduction history (traits hereafter) known to be related to invasion success in Mediterranean regions 
were registered for each alien species (Lloret et al. 2005; Gassó et al. 2009): dispersal syndrome (zoochorous/non-zoochorous), vegetative reproduction (yes/no), life-form classification (trees-buds $25 \mathrm{~cm}$ above soil level, shrubs-buds no more than $25 \mathrm{~cm}$ above soil level, geophytes-buds below ground, annual plants and vines), introduction pathway (gardening/agriculture/forestry/weed) and biogeographical region of origin. We obtained all the above information (Online resource 1-Table S1) from Castroviejo et al. (1986), Bolós et al. (1993) and Sanz-Elorza et al. (2004).

\section{Landscape and local variables}

We characterized each plot with nine landscape and local variables commonly used to explain plant invasion patterns (Deutschewitz et al. 2003; Pino et al. 2005; McDonald and Urban 2006). The landscape characteristics were relative percentage of forest, urban and agriculture use, Shannon's diversity index of land uses and minimum distance to main roads and motorways (i.e. opposite to road proximity). We calculated all landscape variables within 250, 500, 1,000 and 2,000 m buffer areas from the edge plot using ArcGIS 10 (ESRI 2011). These distances are within the range (250-1,500 m) used in studies on alien plants (Sullivan et al. 2005; Bartuszevige et al. 2006; Kumar et al. 2006). The percentage of land use and the diversity index were based on the 3rd version of the Land Cover Map of Catalonia (www.creaf.uab.cat/mcsc), obtained by digitizing 2005 colour ortho-images. We obtained road proximity using the $1: 50,000$ topographic map of Catalonia (ICC 2004).

The selected local variables were aspect, disturbance level, forest type (mixed/deciduous, oak/evergreen, oak/pine) and edge type (closed/open). We obtained aspect for each pair of plots. To facilitate interpretation, we transformed aspect into a NE-SW axis (Beers et al. 1966) with values of 0 at the NE aspect where radiation and evapotranspiration are expected to be lower and values of 2 at the SW orientation. Slope and aspect could interact to change radiation levels in forest edges. As slopes never exceeded $12^{\circ}$, we regarded aspect as a sufficient indicator of light penetration. We visually quantified disturbance level for each plot using a categorical range of 6 levels: undisturbed, very low (e.g. animal trampling), low (e.g. sporadic debris), medium (e.g. moderate human trampling and debris), high (e.g. high human trampling and accumulation of debris) and very high (e.g. dumping, logging and high soil disturbance). We also visually classified the edge type as open or closed depending on understory height and density.

\section{Statistical analysis}

Invasion patterns in edge and interior plots and their relation to landscape and local characteristics

We explored the association of alien and native species richness, proportion of alien species and Sørensen's similarity index with landscape and local variables by multimodel inference (Burnham and Anderson 2002) and variance partitioning techniques (Mood 1969) based on generalized linear models (GLM). For both analyses, we built independent GLMs for edge and interior plot data subsets with the exception of the models for the similarity indices which combine information from both plot types. We modelled the error terms of species richness variables using a Poisson distribution, which is typically used for count data (Gelman and Hill 2007). For similarity indices and alien species proportion we used normal and binomial distributions, respectively. None of the GLMs exhibited spatial autocorrelation in the residuals according to Moran's index $(\mathrm{I}<0.4)$.

Prior to modelling we identified the most influential buffer distance for each variable according to Pearson's correlation coefficients (Online resource 1-Table $\mathrm{S} 2$ ). We selected $1,000 \mathrm{~m}$ as the best compromise for all variables across buffer distances. We then checked the independent variables for collinearity using pairwise correlation tests, excluding correlation values higher than 0.6 (Online resource 1-Table S3).

Variance partitioning techniques indicate the variability explained by the single and shared groups of variables (Mood 1969). Assuming that deviance is a good measure of the variability explained by a model, we set up a GLM for each dependent variable incorporating only landscape variables, only local variables and both of types of variables together. The deviance explained by each model was then used to identify the pure and mixed effects by simple equation systems (Carrete et al. 2007).

Multimodel inference is a model selection method that allowed us to identify the best possible models and rank all independent variables according to their 
influence on each dependent variable. We performed multimodel inference based on all-subsets selection of GLMs using Akaike's Information Criterion corrected for small samples or large number of predictors (AICc; Burnham and Anderson 2002). For each combination of predictors we calculated the Akaike weight of evidence $\left(\mathrm{w}_{\mathrm{i}}\right)$. Considering the best models given the selected predictors (delta $<2$ : all models within 2 AICc units from the best model), the weight of evidence $\left(\mathrm{w}_{\mathrm{i}}\right)$ of each predictor can be estimated as the sum of the model AICc weights across all models in which the selected predictor appeared (Burnham and Anderson 2002). The predictor with the highest $w_{i}$ (i.e. the closest to one) gets the highest weight of evidence to explain the response variable with the given data compared to the rest (i.e. the highest relative importance).

We also used multimodel inference to estimate regression coefficients and their unconditional confidence intervals (with the adjusted standard error) within the best models subset (delta $<2$; Burnham and Anderson 2002). We calculated the coefficient for a given predictor as the sum of the predictor's coefficient multiplied by the weight of evidence, across all possible models where the predictor is present (Burnham and Anderson 2002).

\section{Alien plant traits and their relation to landscape and local characteristics}

We explored the differences in alien trait proportions (i.e. \% of species with zoochorous dispersal, vegetative reproduction, and gardening/agriculture pathway of introduction) between invaded edge and interior plots by paired Wilcoxon's signed-rank tests, after verifying the absence of normality $(n=48)$. Then, we used the Fourth-corner method (Legendre et al. 1997; Dray and Legendre 2008) to explore the association of landscape and local variables with alien plant traits at edge plots. This type of multivariate analysis allows the quantification of the relation between two matrices, R-landscape and local characteristics at each edge plot and Q-alien species traits, through a third matrix, L, which stores the distribution of species among edge plots. We used the permutation model $\mathrm{q} 1 / \mathrm{I}$, where cell values were permuted within the columns (species) of the L-matrix (Legendre et al. 1997; Aubin et al. 2009). This model tests the null hypothesis that species traits are randomly distributed with respect to characteristics of the sites. The alternative hypothesis states that individuals with specific traits are distributed according to their environmental preferences. Specifically, we expected an association of annual species with disturbed sites and close to roads (Lake and Leishman 2004; Jauni and Hyvönen 2012), as well as a significant relationship between the relative proportion of land uses and the pathway of introduction. The later association might reflect the effect of landscape type on propagule diversity arriving to the edge. We corrected probabilities of all statistics with the Holm's procedure after 9999 permutations. We performed all statistical analyses with the R software (R Development Core Team 2011) using the ADE4 package for the Fourth-corner method (Dray and Dufour 2007), the package MuMIn for some procedures of the multimodel inference method and the package VEGAN as the base code for deviance partitioning.

\section{Results}

Invasion patterns in edge and interior plots and their relation to landscape and local characteristics

The total pool of native and alien species found in the plots was 150 and 48 , respectively. The mean $( \pm \mathrm{SE})$ proportion of alien species was $16 \%( \pm 1.10)$ and the mean $( \pm \mathrm{SE})$ species richness per plot was 16.04 ( \pm 0.42$)$ for native species and $2.48( \pm 0.16)$ for alien species.

Alien species identity varied between edge and interior plots: 25 alien species were found only in the edge plots while four species were found only in the interior plots (Online Resource 1-Table S1). The most abundant alien species in edge plots were Celtis australis L. (46\% of plots), Lonicera japonica Thunb. (34\%) and Ligustrum japonicum Thunb. (31\%), while in interior plots Celtis australis (39\%), Ligustrum japonicum (24\%), Prunus domestica L. (11\%) and Solanum chenopodioides Lam. (11\%) were the most abundant alien species.

The GLMs for species richness and proportion of alien species explained a small proportion of the variance (Table 1). The major correlates (i.e. higher weight of evidence) for alien species richness were edge type and road proximity (Table 1). Specifically, 
we found both higher alien species richness and proportion in closed edges at high road proximity (i.e. low minimum distance to main roads). Major correlates for native species richness were disturbance and edge type (Table 1). In contrast to alien species richness, higher native species richness was found in the least disturbed open edges. The variables best explaining alien species richness were similar for edge and interior plots.

Species similarity between edge and interior plots was lower for alien $(S=0.24 \pm 0.03)$ than for native species $(\mathrm{S}=0.59 \pm 0.01 ; \mathrm{W}=862.50, P<0.0001)$, although this could be an artefact of Sørensen's index as it yields lower similarity values when species richness is low. Nevertheless, this bias should not affect the relationship to landscape and local variables. Similarity in alien species was mainly related to higher road proximity, whereas similarity in native species was associated with closed edges (Table 1).

Although the deviance partitioning analysis also showed a low explanatory strength of the selected variables, it yielded a clear pattern: the pure effects of the landscape predictors on alien species richness were higher than the effects of the local predictors. The opposite was observed for native species richness (Table 1). The mixed effects of the landscape and local groups of predictors were very small.

Alien plant traits in forest edges and their relation to landscape and local characteristics

Most alien species occurring in the edge plots were trees (50\% of species found), with zoochorous dispersal $(60 \%)$, native to East Asia (18\%) and introduced for gardening (66\%). Furthermore, half of the alien species had vegetative reproduction. Alien species found in the interior plots showed a similar spectrum of traits to those occurring in the edge plots: $61 \%$ of species were trees, $82 \%$ zoochorous, $36 \%$ came from East Asia and $68 \%$ were introduced through gardening. Comparing invaded paired plots, the proportion of zoochorous species was significantly higher in the interior plots $(0.92 \pm 0.03)$ than in the edge $(0.82 \pm 0.03 ; \mathrm{W}=68, P<0.01)$. The same pattern occurred for species coming via agricultural introduction (Interior: $0.48 \pm 0.05$; Edge: $0.21 \pm$ $0.03, \mathrm{~W}=179, P<0.0001)$. However, the proportion of species was higher in the edge plots than those in the interior for species with vegetative reproduction
(Interior: $0.10 \pm 0.03$; Edge: $0.32 \pm 0.04, \quad \mathrm{~W}=$ 497.50, $P<0.0001)$ and introduced for gardening (Interior: $0.48 \pm 0.06$; Edge: $0.65 \pm 0.04, \mathrm{~W}=727.50$, $P<0.01)$.

Fourth-corner analyses revealed a clear association between species traits and both landscape and local variables (Table 2, Online Resource 1-Table S4). All variables except forest type and urban use were correlated with at least one alien species trait (Table 2). Life form was related to disturbance, percentage of agriculture use and land use diversity (Table 2). For instance, geophytes were present in more disturbed sites while vines were concentrated in the least disturbed areas (Table 2). Introduction pathway was only related to landscape variables (Table 2). For example, species of Mediterranean origin introduced through agriculture were positively associated with a high percentage of agriculture in the surrounding landscape matrix. In contrast, the presence of gardening species was positively associated with the percentage of forest use and negatively associated with road proximity (i.e. positive association with minimum distance to main roads; Table 2).

\section{Discussion}

Landscape characteristics are highly associated with plant invasions in forest edges

In contrast to native species richness, alien species richness demonstrated a stronger association with landscape characteristics than with local properties. The main landscape correlate related to the level of invasion (i.e. alien species richness and proportion) was road proximity. This association has also been found at different spatial scales of resolution from landscape to regional studies (Pino et al. 2005; Bradley and Mustard 2006; Ibáñez et al. 2009; Souza et al. 2011). High road density or proximity to roads might facilitate seed dispersal by humans or vehicles and therefore increase alien species spread (Bradley and Mustard 2006).

The local characteristic with the largest association with invasion was edge type. Alien species richness and proportion of alien species were larger in closed edges. This association could be explained by two non-exclusive effects. First, the closed structure in forest edges could be the result of the rapid growth of 


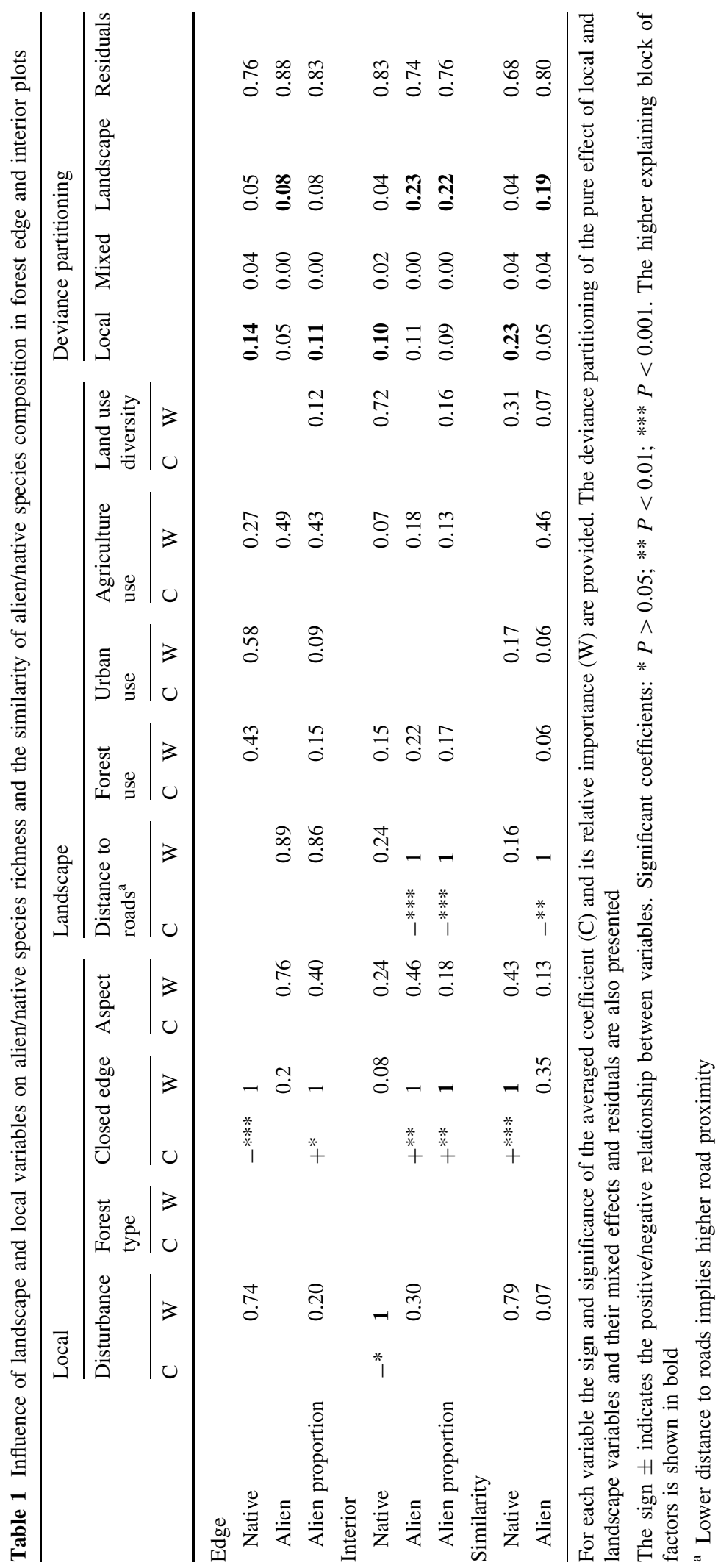


Table 2 Relationship among plant traits' levels and local and landscape variables

\begin{tabular}{|c|c|c|c|c|c|c|c|}
\hline & Closed edge & Disturbance & Aspect & Distance to roads & Forest use & Agriculture use & Land use diversity \\
\hline \multicolumn{8}{|l|}{ Life form } \\
\hline Shrub & & & & & & & + \\
\hline Geophyte & & + & & & & & \\
\hline Annual & & & & & & + & \\
\hline Vine & & - & & & & & \\
\hline \multicolumn{8}{|l|}{ Pathway } \\
\hline Agriculture & & & & - & - & + & \\
\hline Gardening & & & & + & + & - & \\
\hline Unintentionally & & & & & & + & \\
\hline \multicolumn{8}{|l|}{ Reproduction } \\
\hline Vegetative & & & & & & - & \\
\hline \multicolumn{8}{|l|}{ Dispersion } \\
\hline Zoochorous & & & + & & & + & \\
\hline \multicolumn{8}{|l|}{ Region of origin } \\
\hline America & & & & + & & - & \\
\hline Europe & & + & & & & & \\
\hline South America & & & & - & & & \\
\hline East Asia & + & & & + & & & \\
\hline Mediterranean & & & & & & + & \\
\hline South Africa & & & & & & - & \\
\hline
\end{tabular}

Only significant correlations at the $5 \%$ significance level after Holm correction are presented. The sign indicates if the statistic is above $(+)$ or below $(-)$ the expected value based on the mean of 9999 permutations

established alien species that build a wall of vegetation (Brothers and Spingarn 1992). Second, closed edges offer lower radiation but higher water availability and thus provide less stressful conditions than open forest edges (Didham and Lawton 1999), thereby facilitating the establishment of shade-tolerant species commonly introduced via gardening which are expanding in very diverse forests (Martin et al. 2009).

Similarity of alien species composition between the forest edge and the interior also showed a stronger association with characteristics of the landscape than with local properties. Similarity of alien species was also associated with a landscape predictor, namely road proximity. Nearby roads may provide more opportunities for edge disturbance and propagule pressure from edges to the interior. On the other hand, similarity of native species was higher in closed forest edges. Closed edges promote low contrasting local conditions between the edge and the interior (e.g. comparable water and light conditions) that facilitates the establishment of similar native plant communities (Didham and Lawton 1999; Harper et al. 2005). These findings suggest that in contrast to native species, the establishment of alien plants in the forest interior is not highly limited by the local conditions. In fact, the forest interior may be invaded at high levels of propagule pressure demonstrating that forest edges are not a barrier to invasion (Guirado et al. 2006).

The association between alien plant traits and landscape

Many studies have pointed out that alien species traits related to successful invasion are habitat dependent (Kolar and Lodge 2001; Lake and Leishman 2004; Lloret et al. 2005; Jauni and Hyvönen 2012). We found that some alien species traits were related to specific local variables such as disturbance, edge type and aspect. Nevertheless, our findings are not entirely consistent with previous studies, indicating that the association between species traits and habitat might be relatively idiosyncratic. For instance, alien species in disturbed plots tended to be geophytes, which is contrary to previous suggestions that annual plants 
should be more abundant (Lake and Leishman 2004; Jauni and Hyvönen 2012). However, this observation is consistent with the fact that herbaceous perennial plants with underground structures are good invaders because these structures are often associated with effective clonal growth mediated by disturbance (Gassó et al. 2009). Nevertheless, we observed differences in species traits between alien species occurring in edge and interior forest habitats. Agriculture and zoochorous species were found more frequently in the interior, while species with vegetative reproduction or with a gardening pathway of introduction were in the edge. This finding partially agrees with previous studies which suggest zoochorous and gardening species are concentrated in the forest interior (Brothers and Spingarn 1992; Cadenasso and Pickett 2001). The authors of the above mentioned investigations based their conclusions on observations of species occurrence or dispersal distances, although they did not statistically compare proportions or cumulative abundances between edge and interior. In fact, it seems difficult to find general patterns of alien traits dominance between the forest edge and interior. First, the predominance of alien species traits in the forest edge or interior may depend on the gardening and agriculture practices of the area. In our study area most agricultural alien species are fruit trees so it is possible that individuals found in the forest interior were legacies from former agriculture land. Second, alien species are rarely in equilibrium with their environment and as we observed, their spread depends heavily on constant propagule pressure from the nearby landscape. Thus, it is also possible that gardening species are still in the process of expansion and that they have not yet reached their potential penetration into the forest interior (Martin et al. 2009).

The Fourth-corner analysis also suggested that most predominant alien species traits, and probably the most successful ones in our study area, are linked to the landscape characteristics surrounding forest edges. Plots with higher agricultural area in the surrounding landscape primarily had annual species introduced for agriculture, of Mediterranean origin and without vegetative reproduction. These traits are commonly shared by crop species. Surprisingly, gardening origin was significantly associated with forest use but not with urban use. As transects were placed on urban-forest edges, it is possible that this setup represented a limited gradient of the percentage of urban land-use in the landscape. On the other hand, as gardening species could successfully establish themselves in the forest edge, forest habitats could be also a source of propagules for these species.

Currently, most risk analyses to identify invasive plants focus on species traits (Kolar and Lodge 2001; Lloret et al. 2005; Hayes and Barry 2007) and the degree of climate match between the native and recipient area (Scott and Panetta 1993; Thuiller et al. 2005). Our results indicate that risk analyses must also explore the characteristics of the landscape of the recipient area because it highly defines the most likely origin of potential invasive species.

\section{Conclusions}

Invasion in forest edges could be seen as a spatial hierarchical process where landscape characteristics control main differences in the level of invasion, which is also influenced by local site-specific conditions such as the edge structure (McDonald and Urban 2006; Milbau et al. 2008). Overall we found alien species richness, proportion of alien species and composition differences between the forest edge and interior to be highly dependent on the landscape surrounding the edge. This finding suggests that invasion at these sites is a dynamic process primarily related to the propagule pressure from the surrounding landscape. High humanalteration of the landscape contributes to further expansion of alien plant species from forest edges into the interior. The global trend towards forest fragmentation, which increases the length of the interfaces between urban and forest areas, will exacerbate plant invasions by gardening species (Martin et al. 2009). Thus, management of plant invasion must also consider the landscape adjacent to natural areas in order to reduce the propagule pressure from humanderived land-uses. Possible landscape management measures could include changes in gardening practices or constant monitoring of plant invasion in urbanforest interfaces.

The analysis of plant traits related to invasiveness has been one of the main focuses in invasion biology (Hayes and Barry 2007; Pyšek and Richardson 2007) and the basis for invasion risk analysis. However, identifying general patterns is complicated as many plant traits associated with invasion are dependent on the habitat type and the stage of invasion (Kolar and 
Lodge 2001; Lloret et al. 2005; Gassó et al. 2009; Jauni and Hyvönen 2012). Our results indicate that these risk analyses should also include characteristics of the landscape matrix of the recipient region because successful or more abundant alien plant traits are likely to be different depending on the surrounding landscape (Vilà and Ibáñez 2011).

Acknowledgments We are very grateful to the Global Change Ecology Lab of University of Michigan whose comments significantly improved the manuscript. This research was partially funded by the Spanish Ministerio de Ciencia e Innovación projects Consolider-Ingenio MONTES (CSD2008-00040) and RIXFUTUR (CGL2009-7515), and the Junta de Andalucía project RNM-4031. We also thank two anonymous reviewers for their comments and advice.

\section{References}

Aubin I, Ouellette M, Legendre P, Messier C, Bouchard A (2009) Comparison of two plant functional approaches to evaluate natural restoration along an old-field-deciduous forest chronosequence. J Veg Sci 20:185-198

Bartuszevige AM, Gorchov DL, Raab L (2006) The relative importance of landscape and community features in the invasion of an exotic shrub in a fragmented landscape. Ecography 29:213-222

Beers TW, Dress PE, Wensel LC (1966) Aspect transformation in site productivity research. J For 64:691-692

Bolós O, Vigo J, Masalles RM, Ninot JM (1993) Flora Manual dels Països Catalans, 2nd edn. Pòrtic, Barcelona

Bradley BA, Mustard JF (2006) Characterizing the landscape dynamics of an invasive plant and risk of invasion using remote sensing. Ecol Appl 16:1132-1147

Brothers TS, Spingarn A (1992) Forest fragmentation and alien plant invasion of Central Indiana old-growth forests. Conserv Biol 6:91-100

Burnham KP, Anderson DR (2002) Model selection and multimodel inference: a practical information-theoretic approach, 2nd edn. Springer, New York

Cadenasso ML, Pickett STA (2001) Effect of edge structure on the flux of species into forest interiors. Conserv Biol 15:91-97

Carrete M, Grande JM, Tella JL, Sánchez-Zapata JA, Donázar JA, Díaz-Delgado R, Romo A (2007) Habitat, human pressure, and social behavior: partialling out factors affecting large-scale territory extinction in an endangered vulture. Biol Conserv 136:143-154

Castroviejo S, Lainz M, López G, Montserrat P, Muñoz F, Paiva J, Villar L (1986) Flora Ibérica. Real Jardín BotánicoCSIC, Madrid

Deutschewitz K, Lausch A, Kühn I, Klotz S (2003) Native and alien plant species richness in relation to spatial heterogeneity on a regional scale in Germany. Glob Ecol Biogeogr 12:299-311

Didham RK, Lawton JH (1999) Edge structure determines the magnitude of changes in microclimate and vegetation structure in tropical forest fragments. Biotropica 31:17-30
Didham RK, Tylianakis JM, Gemmell NJ, Rand TA, Ewers RM (2007) Interactive effects of habitat modification and species invasion on native species decline. Trends Ecol Evol 22:489-496

Dray S, Dufour A (2007) The ade4 package: implementing the duality diagram for ecologists. J Stat Softw 22:1-20

Dray S, Legendre P (2008) Testing the species traits-environment relationships: the fourth-corner problem revisited. Ecology 89:3400-3412

ESRI (2011) ArcGIS Desktop: Release 10. Environmental Systems Research Institute, Redlands, CA

Ewers RM, Didham RK (2006) Confounding factors in the detection of species responses to habitat fragmentation. Biol Rev 81:117-142

Fraver S (1994) Respuestas de la vegetación a lo largo de gradientes de borde-hacia-el interior de bosques latifoliados mixtos de la cuenca del río Roanoke, en Carolina del Norte. Conserv Biol 8:822-832

Gassó N, Sol D, Pino J, Dana ED, Lloret F, Sanz-Elorza M, Sobrino E, Vilà M (2009) Exploring species attributes and site characteristics to assess plant invasions in Spain. Divers Distrib 15:50-58

Gelman A, Hill J (2007) Data analysis using regression and multilevel/hierarchical models, 1st edn. Cambridge University Press, New York

Guirado M, Pino J, Roda F (2006) Understorey plant species richness and composition in metropolitan forest archipelagos: effects of forest size, adjacent land use and distance to the edge. Glob Ecol Biogeogr 15:50-62

Harper KA, McDonalad SE, Burton PJ, Chen J, Brosofske K, Sanders SC, Euskirchen E, Roberts D, Jaiteh M, Esseen P (2005) Edge influence on forest structure and composition in fragmented landscapes. Conserv Biol 19:768-782

Hayes KR, Barry SC (2007) Are there any consistent predictors of invasion success? Biol Invasions 10:483-506

Hobbs RJ, Huenneke LF (1992) Disturbance, diversity, and invasion: implications for conservation. Conserv Biol 6: 324-337

Ibáñez I, Silander JA Jr, Allen JM, Treanor SA, Wilson A (2009) Identifying hotspots for plant invasions and forecasting focal points of further spread. J Appl Ecol 46:1219-1228

ICC (2004) Base topogràfica 1:50.000 v.3.1. Barcelona, Spain

Jauni M, Hyvönen T (2012) Interactions between alien plant species traits and habitat characteristics in agricultural landscapes in Finland. Biol Invasions 14:47-63

Kolar CS, Lodge DM (2001) Progress in invasion biology: predicting invaders. Trends Ecol Evol 16:199-204

Kumar S, Stohlgren TJ, Chong GW (2006) Spatial heterogeneity influences native and nonnative plant species richness. Ecology 87:3186-3199

Lake JC, Leishman MR (2004) Invasion success of exotic plants in natural ecosystems: the role of disturbance, plant attributes and freedom from herbivores. Biol Conserv 117: $215-226$

Legendre P, Galzin R, Harmelin-Vivien ML (1997) Relating behavior to habitat: solutions to the fourth-corner problem. Ecology 78:547-562

Lloret F, Medail F, Brundu G, Camarda I, Moragues E, Rita J, Lambdon P, Hulme PE (2005) Species attributes and invasion success by alien plants on Mediterranean islands. J Ecol 93:512-520 
Martin PH, Canham CD, Marks PL (2009) Why forests appear resistant to exotic plant invasions: intentional introductions, stand dynamics, and the role of shade tolerance. Front Ecol Environ 7:142-149

McCune B, Grace J (2002) Analysis of ecological communities. Mjm Software Design, Gleneden Beach

McDonald RI, Urban DL (2006) Edge effects on species composition and exotic species abundance in the North Carolina piedmont. Biol Invasions 8:1049-1060

Milbau A, Stout JC, Graae BJ, Nijs I (2008) A hierarchical framework for integrating invasibility experiments incorporating different factors and spatial scales. Biol Invasions 11:941-950

Mood AM (1969) Macro-analysis of the American educational system. Oper Res 17:770-784

Ohlemüller R, Walker S, Bastow Wilson J (2006) Local vs regional factors as determinants of the invasibility of indigenous forest fragments by alien plant species. Oikos 112:493-501

Olarieta JR, Rodríguez-Valle FL, Tello E (2008) Preserving and destroying soils, transforming landscapes: soils and landuse changes in the Vallès County (Catalunya, Spain) 1853-2004. Land Use Policy 25:474-484

Pino J, Font X, Carbó J, Jové M, Pallarès L (2005) Large-scale correlates of alien plant invasion in Catalonia (NE of Spain). Biol Conserv 122:339-350

Pyšek P, Richardson DM (2007) Traits associated with invasiveness in alien plants: where do we stand? In: Nentwig W (ed) Biological invasions. Springer, Berlin, pp 97-125
R Development Core Team (2011) R: A language and environment for statistical computing. R Foundation for Statistical Computing. Vienna, Austria. ISBN 3-900051-07-0. http://www.R-project.org/

Sanz-Elorza M, Dana ED, Sobrino E (2004) Atlas de las plantas alóctonas invasoras en España. Dirección General para la Biodiversidad, Madrid

Scott JK, Panetta FD (1993) The Australian weed status of Southern African plants. J Biogeogr 20:87-93

Souza L, Bunn WA, Simberloff D, Lawton RM, Sanders NJ (2011) Biotic and abiotic influences on native and exotic richness relationship across spatial scales: favourable environments for native species are highly invasible. Funct Ecol 25:1106-1112

Sullivan JJ, Timmins SM, Williams PA (2005) Movement of exotic plants into coastal native forests from gardens in northern New Zealand. New Zeal J Ecol 29:1-10

Thuiller W, Richardson DM, Pysek P, Midgley GF, Hughes GO, Rouget M (2005) Niche-based modelling as a tool for predicting the risk of alien plant invasions at a global scale. Glob Change Biol 11:2234-2250

Thuiller W, Richardson DM, Rouget M, Procheş Ş, Wilson JRU (2006) Interactions between environment, species traits and human uses describe patterns of plant invasions. Ecology 87:1755-1769

Vilà M, Ibáñez I (2011) Plant invasions in the landscape. Landsc Ecol 26:461-472

With KA (2004) Assessing the risk of invasive spread in fragmented landscapes. Risk Anal 24:803-815 